\title{
Attitudes and Experiences of Men With Prostate Cancer on Risk in the Context of Injuries Related to Community-Based Football-A Qualitative Study
}

\author{
Mette Rørth, Tine Tjørnhøj-Thomsen, Prue Cormie, John L. Oliffe, and Julie Midtgaard
}

\begin{abstract}
Although football training may be a potent strategy for health promotion in older men, the considerable risk of injuries may constitute a barrier for referral of clinical populations. The current study explored the attitudes of men with prostate cancer on risk in the context of injuries related to participating in a community-based football program. Four videotaped focus group interviews and three individual in-depth telephone interviews were carried out with men with prostate cancer $(n=35$; mean age $=68.8)$. The thematic networks technique was used to derive the global theme Injury-induced reinforced masculinity comprising five subthemes: "part of the game," "a good story to tell," "like boys again," "an old, carefree body," and "camaraderie." Collectively, these themes explained how football injuries may reflect masculine ideals in some men with prostate cancer. The study indicates that injuries are largely acceptable to men with prostate cancer, especially those in search of a means for expressing their masculinity.
\end{abstract}

Keywords: focus group, masculinity, rehabilitation, soccer, sport injury

Existing evidence suggests that men with prostate cancer benefit from physical activity and exercise, in terms of both mental health, alleviation of treatment-related side effects, and reduction of prostate cancer mortality (Cormie, Zopf, Zhang, \& Schmitz, 2017; Shephard, 2016). However, less than half of all men with prostate cancer meet the recommended level of physical activity (i.e., $150 \mathrm{~min} /$ week) (Chipperfield et al., 2013), indicating that the current approaches, including on-site, supervised, and structured exercise programs, may be suboptimal or inadequate to engage men in positive exercise behaviors long term. As such, novel approaches with the potential to effectively promote physical activity adherence in men with prostate cancer are warranted.

Prostate cancer patients' sense of masculinity is challenged not only by their disease but also by their age, as most men are over 60 years of age when diagnosed (Bechis, Carroll, \& Cooperberg, 2011; van den Hoonaard, 2009). As they age, men are confronted with various challenges in losing their purchase on the masculine capital associated with being young, employed, and in a (hetero) sexual relationship (Connell, 1995; Spector-Mersel, 2006; van den Hoonaard, 2009). Cognizant of this background, initiatives that reinforce some masculine ideals such as engaging with sports and other action-oriented activities may be central to men's prostate cancer rehabilitation (Bruun et al., 2014; Cormie et al., 2016; Handberg, Lomborg, Nielsen, Oliffe, \& Midtgaard, 2015).

Masculine ideals are often expressed and reproduced in sport, including soccer, where violence, pain, and injuries are legitimate

Rørth and Midtgaard are with the University Hospitals Centre for Health Research, Copenhagen University Hospital Rigshospitalet, Copenhagen, Denmark. TjørnhøjThomsen is with the National Institute of Public Health, University of Southern Denmark, Copenhagen, Denmark. Cormie is with the Mary Mackillop Institute for Health Research, Australian Catholic University, Melbourne, Australia. Oliffe is with the School of Nursing, University of British Columbia, Vancouver, British Columbia, Canada. Midtgaard is also with the Dept. of Public Health, University of Copenhagen, Copenhagen, Denmark. Address author correspondence to Julie Midtgaard at julie@ucsf.dk. and meaningful (Bryson, 1987; Connell, 2008; Theberge, 1997). Manly tolerance toward the risk of injury is rewarded by society and risk tolerance, in general, is perceived to be normative for athletes and an inherent part of male athlete's identity (Kroshus, Garnett, Hawrilenko, Baugh, \& Calzo, 2015). This perception is true not only for professional athletes but also at all levels of sports (Young, 2004). Researchers have drawn a parallel between the culture of injury in sports and the military, where fallen soldiers with injuries are hailed as heroes, their actions revered as manly and selfless (Bradley, Baur, Banford, \& Postlethwaite, 2013; Sanderson, Weathers, Grevious, Tehan, \& Warren, 2016; Smith \& Sparkes, 2005; Young, McTeer, \& White, 1994). Taking risks develops personal characteristics such as courage, competitiveness, integrity, and composure, all of which many men desire and claim by demonstrating a willingness to risk physical injury and/or play injured (Young, 2004; Young et al., 1994).

This knowledge, including burgeoning evidence on the superiority of recreational football (i.e., soccer) in the achievement of health effects in healthy individuals including untrained, older men (Krustrup et al., 2009), inspired us to develop the "FC (football club) Prostate" research initiative. The idea was to introduce recreational community-based football as a novel approach to prostate cancer rehabilitation characterized by a time-unlimited intervention, continuous enrollment of participants, and mobilizing of local resources and partners using existing infrastructure for physical activity; an approach which we hypothesized may increase participation and retention in men with prostate cancer (Bruun et al., 2014). A Phase III, multicenter randomized trial examining the effectiveness of community-based football as a means to improve quality of life, bone health, and the adoption of physical activity in men with prostate cancer is currently ongoing (Bjerre et al., 2016). A Phase II trial preceding the current study documented that football had a positive impact on the physical and mental well-being of men with prostate cancer and promoted the maintenance of physical activity (Uth, Hornstrup, Christensen, Christensen, Jorgensen, Helge, et al., 2016; Uth, 
Hornstrup, Christensen, Christensen, Jorgensen, Schmidt, et al., 2016). Moreover, a qualitative evaluation component showed that football mitigated some of the population's barriers to participation in rehabilitation by providing a context that makes it possible to strive for normalization and a feeling of being in control (Bruun et al., 2013). However, three adverse events classified as serious injuries occurred in participants during the Phase II trial (Uth, Hornstrup, Christensen, Christensen, Jorgensen, Schmidt, et al., 2016). This automatically raised concerns in the research team regarding acceptability and safety, including how to promote and demonstrate benefit over risk for program participants.

Bearing in mind that men with prostate cancer undergoing androgen deprivation therapy have a quadruple risk of bone fractures (López et al., 2005), the known risk of football injuries could well constitute a significant barrier in clinical referral and implementation of the program. Moreover, from the sport psychology literature, we know that sports injuries can be difficult to overcome and may lead to isolation and considerable psychological distress (Covassin, Beidler, Ostrowski, \& Wallace, 2015; Putukian, 2016). Most research on sports injuries, however, involve young professional athletes in competitive sport (Christakou \& Lavallee, 2009; Drummond, 2002; Podlog, Heil, \& Schulte, 2014), whereas the psychological response to injuries sustained in recreational sport in nonprofessionals, especially in older people, is poorly understood. Therefore, the aim of this study was to describe how men with prostate cancer view risk of injury related to participation in a community-based football intervention.

\section{Methods}

Videotaped focus group interviews were chosen to generate multiple stories and diverse experiences related to participants' attitudes toward the risk of injuries based on dynamic and interactive exchanges among participants (Crossley, 2003). Moreover, individual in-depth telephone interviews were carried out to explore the experience of a football injury in participants who had sustained a serious injury while playing football in the community-based football intervention. Data collection occurred between March and May 2016. The sample consisted of 35 men with prostate cancer (regardless of age, treatment status, and time since diagnosis) who participated in a community-based football intervention involving 1-hour, twice weekly sessions for a minimum of 6 months as part of an ongoing Phase III trial (i.e., The FC Prostate Community Trial) (Bjerre et al., 2016).

Focus group participants received a letter of invitation to participate in the study personally from M. Rørth or from their football coach. Participants were not required to respond to the invitation, but simply attend if they wanted to participate. The focus group interviews were videotaped and took place at the local FC immediately after practice and included all the players present that day. Participants, whose statements were included in the final report, were offered the opportunity to rephrase their original statements; however, none of the men wished to make any adjustments.

Two different interview guides with overlapping themes were developed based on a literature review of prostate cancer, sports injuries, and masculinity. The interview guide for the focus group interviews was intended to stimulate dynamic and interactive conversations, exposing various perspectives and attitudes toward injuries (e.g., "How do you define an injury?" and "How do you manage the risk of being injured?"). The interview guide for the individual interviews centered on the personal experience of being seriously injured while playing football in the community-based football intervention, and used a narrative interview technique to let the interviewee control the direction, content, and pace of the interview (Anderson \& Kirkpatrick, 2016). Initial questions explored general experiences with sports injuries (e.g., "What experience of sports injuries did you have earlier in your life?"), whereas later questions delved into more sensitive topics such as body image and disease (e.g., "How are you affected by your current injury?").

M. Rørth conducted all interviews and wrote field notes immediately after each interview. Filed notes included reflections related to casual conversations, observation of nonverbal aspects of research context, and issues that should be explored in subsequent interviews.

\section{Data Analysis}

Data were analyzed by network thematic analysis (Attride-Stirling, 2001), using the web-like network as an organizing principle and an illustrative tool in the interpretation of (the risk of) how men with prostate cancer view risk of injury related to participation in community-based football. The thematic coding was conducted using anonymized, precise verbatim transcripts and transcripts of field notes and employed steps outlined by Attride-Stirling (2001), with QSR NVivo 11 used to upload, organize, and code the data (QSR International, Doncaster, Victoria, Australia). The thematic coding approach was supplemented by elements from narrative analysis allowing examination of the structure and context of each participant's story. Narrative analysis can take different forms and deals with how protagonists interpret things (Bruner, 1990, p. 51). As the approach gives prominence to human agency and imagination, it is well suited to studies of subjectivity and imagination (Riessman, 1993, p. 5).

M. Rørth conducted the data analysis in intense discussion with J. Midtgaard and T. Tjørnhøj-Thomsen and subsequently P. Cormie and J. L. Oliffe. The initial division and comparison between data collected by means of videotaped focus groups and individual in-depth telephone interviews, respectively, showed few differences because many of the uninjured/active players perceived themselves as currently or previously injured and drew on these experiences in the interviews. As a result, both the focus group and individual interviews were analyzed jointly to distill what prevailed across the participants' accounts.

We initially reduced the data by means of a coding framework based on salient recurrent issues in the text (e.g., football, team, risk-taking) and our preestablished interest in prostate cancer, sports injuries, and masculinity. Subsequently, we reread the coded text segments and abstracted and refined basic themes, which we arranged into similar, coherent higher-order clusters of signification (i.e., organizing themes). Lastly, the issues underlying and relating these organizing themes were identified and named, and a global theme was constructed (i.e., Injury-induced reinforced masculinity). During this entire process, we tried to form as many links and hypotheses as possible through recursive iterative cycles of analytical interpretation. Quotations are presented, together with the corresponding participant pseudonym and age.

\section{Ethics}

Participants provided informed written consent and were assured all avenues had been taken to ensure anonymity. The current study is a qualitative substudy of an ongoing Phase III trial (i.e., The FC Prostate Community Trial) approved by the National Committee 
on Health Research Ethics (file number H-2-2014-099). However, due to the nature of this particular substudy, a separate ethics committee approval was not required.

\section{Results}

\section{Sample Characteristics}

Four videotaped focus group interviews (each involving 5-12 men) were carried out with a total of 32 men with prostate cancer (average age 69.4). The men represented four "FC Prostate" football teams playing in four local clubs in different regions of Denmark. An additional six participants who were seriously injured while playing football in the community-based football intervention were contacted by mail, three of whom agreed to take part in an in-depth individual interview over the telephone. Table 1 shows the characteristics of participants $(n=35)$ across interviews.

\section{Findings}

The current study introduces the global theme Injury-induced reinforced masculinity comprising five subordinate organizing themes: (a) "Part of the game," (b) "A good story to tell," (c) "Like boys again," (d) "An old, carefree body," and (e) "Camaraderie." Collectively, these themes explain how the risk of injury may affirm masculinity in men with prostate cancer participating in a community-based football program. The structure and summary of the analysis are illustrated in Figure 1.

Part of the game. During the interviews, participants repeatedly said that football involved the risk of injury and that without it, football would not be the same; it would not be football. One interviewee stated:

“They're [injuries] something that's inherently part of it, right (...) If you have to go to the doctor afterwards, you have an injury; otherwise it's simply part of the game." (Lasse, 80 years old)

The participants viewed injuries as an intrinsic feature of football. By accepting the invitation to play, the men simultaneously accepted the fact that they might be injured. Participants explained that because injuries are part of the game, football is not for everyone, only for men who can manage getting hurt and willing to take risks. Another participant clarified that:

"It has to hurt once in a while, you know? Otherwise you shouldn't be playing football." - (Oscar, 65 years old)

A few men, however, positioned the football intervention as rehabilitation rather than sport. These men described accepting the risk of injuries, but advocated for special treatment and privileges, that is, access to physiotherapy free of charge and a trained physiotherapist present during training:

"It takes some professional guidance, you know? I mean a physiotherapist or someone you can consult and say, 'I've got a pulled muscle'. Instead of having us more or less walk around with our injuries and be neglected, saying it'll be alright, you know what I mean?" (Adam, 62 years)

Only one participant was distinctly displeased with being injured and described that his injury had cost more, in terms of what he lost, compared with the potential gains of participating:

"I actually almost thought it was annoying in my case, the fact that it [the injury] spread to my private life, you know?" (Adam, 62 years)

Moreover, this particular participant lobbied governance from the program coordinators to accommodate his views and practices. Specifically, this participant requested that the risk of being injured should be addressed more explicitly during enrollment and include a warning of the possible negative consequences of being injured (i.e., reduced mobility and persisting pain that may interfere with activities of daily living).

A good story to tell. Participants' stories bypassed their prostate cancer and being older and retired. Instead, they claimed athlete status chronicling sports injuries as a sacrifice "real" men were willing to make. The following statements illustrated how the participants were able to use their injuries to generate stories to assert their masculinity:

Table 1 Characteristics of Participants Across Interviews

\begin{tabular}{|c|c|c|c|c|c|c|}
\hline Interview type & $n$ & $\begin{array}{l}\text { Mean age } \\
\text { [min;max] }\end{array}$ & ADT $(n)$ & $\begin{array}{c}\text { Mean time since diagnosis } \\
\text { (years, months) } \\
\text { [min;max }]\end{array}$ & $\begin{array}{l}\text { Adult football } \\
\text { experience }^{a}(n)\end{array}$ & $\begin{array}{c}\text { MET } \\
\text { minutes/week } \\
{[\text { min;max }]}\end{array}$ \\
\hline Focus group interviews & 32 & $\begin{array}{c}68.8 \\
{[52 ; 80]}\end{array}$ & 15 & $\begin{array}{c}5,7 \\
{[2,3 ; 12,2]}\end{array}$ & 8 & $\begin{array}{c}4388 \\
{[0 ; 12933]}\end{array}$ \\
\hline team 1 & 9 & $\begin{array}{c}66.4 \\
{[60 ; 75]}\end{array}$ & 1 & $\begin{array}{c}5,6 \\
{[2,3 ; 9,6]}\end{array}$ & 1 & $\begin{array}{c}3343 \\
{[792 ; 6786]}\end{array}$ \\
\hline team 2 & 5 & $\begin{array}{c}70.2 \\
{[63 ; 74]}\end{array}$ & 3 & $\begin{array}{c}5,9 \\
{[3,1 ; 12,2]}\end{array}$ & 3 & $\begin{array}{c}7374 \\
{[852 ; 12933]}\end{array}$ \\
\hline team 3 & 12 & $\begin{array}{c}70.2 \\
{[62 ; 76]}\end{array}$ & 7 & $\begin{array}{c}3,9 \\
{[2,7 ; 5,11]}\end{array}$ & 4 & $\begin{array}{c}3089 \\
{[0 ; 6080]}\end{array}$ \\
\hline team 4 & 6 & $\begin{array}{c}68.2 \\
{[52 ; 80]}\end{array}$ & 4 & $\begin{array}{c}6,8 \\
{[3,4 ; 12,1]}\end{array}$ & 0 & $\begin{array}{c}6354 \\
{[3042 ; 8816]}\end{array}$ \\
\hline In-depth interviews & 3 & $\begin{array}{c}70.0 \\
{[67 ; 74]}\end{array}$ & 1 & $\begin{array}{c}\mathbf{6 , 5} \\
{[2,3 ; 11]}\end{array}$ & $\mathbf{0}$ & $\begin{array}{c}1781 \\
{[1074 ; 2424]}\end{array}$ \\
\hline
\end{tabular}

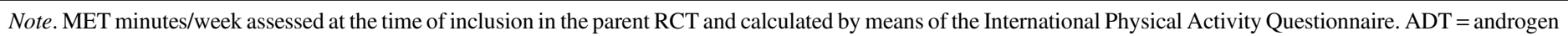
deprivation therapy; MET = metabolic equivalent; RCT $=$ randomized controlled trial.

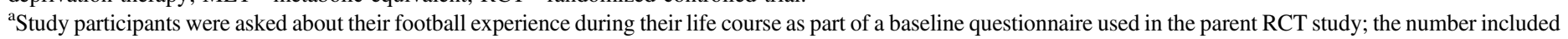
here are participants who reported playing football (regularly) as an adult but not necessarily recently. 


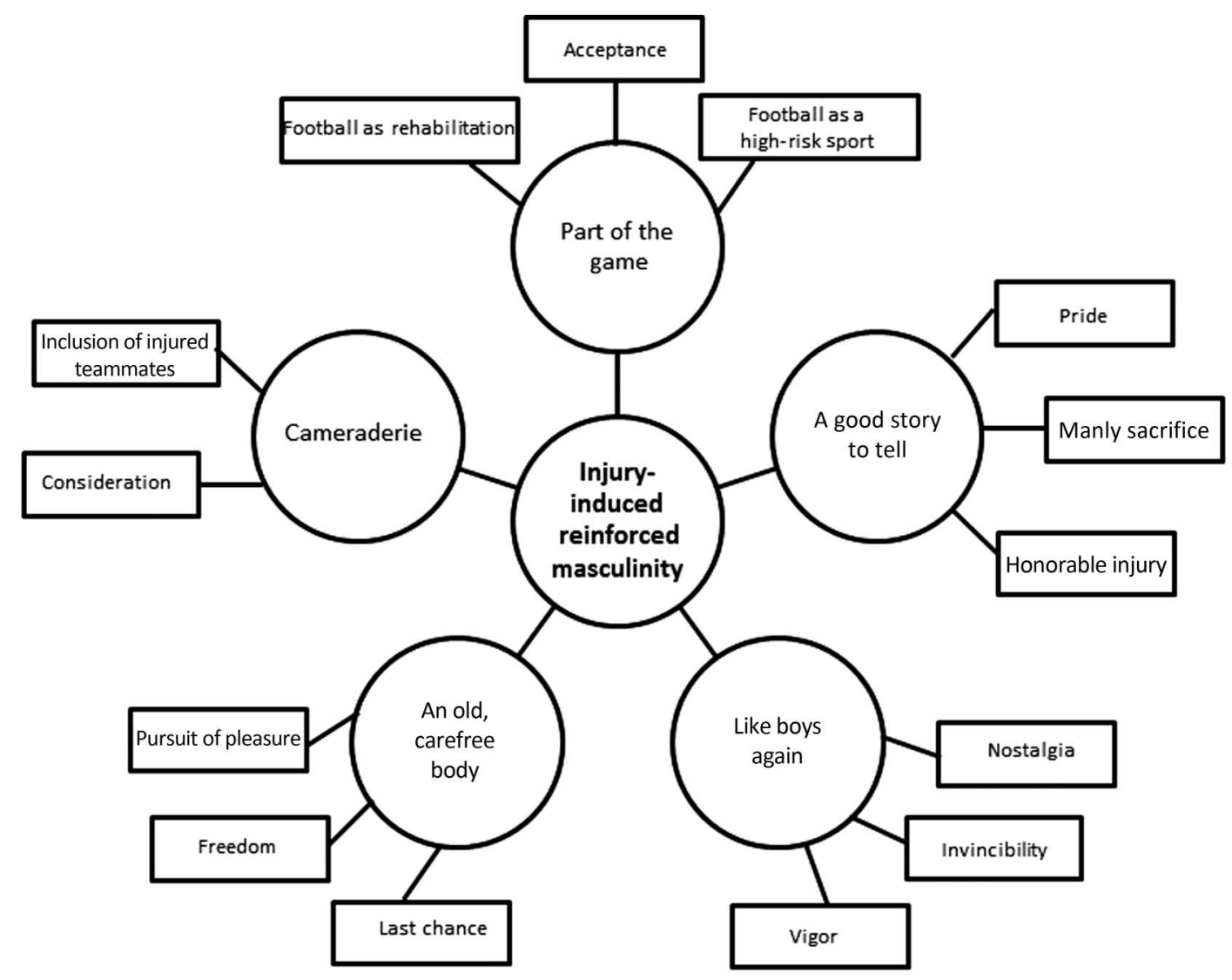

Figure 1 - Structure and summary of the analysis.

"When I got injured I came limping into radiation therapy and the nurses asked if anything had happened to my legs. They were also very interested in how I was doing. Then I told them that is was 'FC Prostate' [name of the community based football program], which of course made them laugh because that was one they hadn't heard before!" (Jacob, 63 years old)

Similarly, another man said,

"It's a bit more fun to say you got a black eye from a fight on the football field rather than because you walked into a door, right?" (Jim, 75 years old)

When the interviewer asked: "So, is it at all possible to be proud of a football injury?," one man responded:

"Yeah, that was actually what I was talking about, a bit more [proud] than if you had fallen off the treadmill." (Mikkel, 69 years old). Another focus group participant noted: "Yeah, at least it's a better story to tell, you know? It's more honourable." (Tobias, 63 years old). Another participant exclaimed: "I would rather die on a football field than in a hospice, no doubt about that!" (Lasse, 80 years old).

Evident in these narratives were the men's distance from noncontact sports injuries or illness-induced morbidities in claiming their ability to compete in contact sports, and narrate the injuries that accompanied their sacrifice.

Like boys again. When discussing injuries, participants often made a distinction between mind and body, stating that it was the body, and not the mind, that gave into injuries and pain, as the following participant quote illustrated:

"We've ( . . ) sustained injuries simply from falling on the ground and have had to crawl off the field because we couldn't continue... it was a sprain, a pulled muscle that made you have to stop. You want to continue, but you simply can't because your body, leg or whatever won't cooperate." (Tobias, 63 years old)

The participants linked their efforts to youth-centric ideals whereby they explained that the injuries occurred because, once they were on the field, they turned into boys again and used their body beyond its capacity:

"When we're out there, you know? You might hear it, right? We become kind of like boys again, you know? And you think you can conquer the world!" (Patrick, 73 years old)

Sports injuries and soreness offered the men familiar ways of sensing their bodies synonymous with their youth. Instead of being a sign that the body was failing, a sports injury supported the men's masculine self, which was something most participants clearly wanted. The narrative of an injured body and a strong, fighting mind were part of the story of a commitment to recovery to a point of being able to compete again. According to many, a sports injury represented vigor and history:

"Look at this [puts his hands in the air] all of my fingers are crooked, you see? It's from when I used to play handball; they are all sprained - twenty times!" (Tobias, 63 years old) 
The body and fingers of this participant told a story of a sports career, the prized bent fingers submitted as evidence testifying the importance of a sporting life and a man who sacrificed himself for the sport.

The sports injuries reminded some participants of the kind of injuries they had when they were younger:

"I just think that it's a reminder, where you say, 'Ah, that's right - I had that kind of injury ten years ago as well.", (Mikkel, 69 years old)

The injuries also reminded men of their present body:

"Sports injuries just make you realise that you've been active and that you have a body." (Janus, 60 years old)

In this regard, playing football afforded some men opportunities to nostalgically look back on injuries pointing to those experiences and their steely resolve for the timeless embrace of those risks.

An old, carefree body. The participants talked about how new bodily opportunities could arise with older age. They explained that they experienced a greater willingness to take risks due to their age including the idea that there was less lifetime to lose if the injury is serious:

"You're more prepared to get an injury because you know what age you've reached? If you get injured, oh well, so be it!" (Mikkel, 69 years old)

The men elaborated that they thought that an injury had less of a negative impact now compared with when they were younger.

"I think it's easier now than when I was 40 because back then I knew that it would be terrible if I broke my leg because then I wouldn't be able to do my job properly. Today I'd say, 'Oh well, ... if I break my leg, it's just bad luck!' Then you have to lie down with your leg in a cast for months until it's healed. I don't think you give any less of yourself, on the contrary! I might give a bit more of myself compared to what I would have earlier." (Mikkel, 69 years old)

Herein participants spoke about the freedoms of an older body unconstrained by the demands of paid work and family provider roles. Along with these freedoms came options for more hedonistic practices in the pursuit of pleasure, and the embrace of the familiar. The participants talked about risk in relative terms reflecting on sports injuries in relation to their bodies versus the risk of not participating in something that significantly had and did matter to them. The older body in this respect was less burdened with worry about injuries because, age adjusted, injuries had fewer implications.

Camaraderie. The men were not directly asked about the community or camaraderie in relation to playing football. Nonetheless they conveyed that this was the most important benefit to their participation in community-based football. One participant stated:

“For us that's [injuries] not a problem! Which you can easily hear! It certainly isn't, really! An injury is such a tiny thing compared to the joy of playing and being together, you know?" (August, 69 years old)

The men's discussion of injuries and the views they shared also clearly indicated that being injured did not necessarily exclude them from the team's camaraderie. In this respect, football was inclusive of injured players, who from the sidelines could show support and partake in the after-game locker room rituals:

"You can easily be part of the camaraderie by standing on the sidelines and such. You're there before the match. You stand and shout during the match and then you might participate in the camaraderie afterwards, you know? So, it doesn't make any difference. Of course, it would be more fun to participate in the match." (Oscar, 65 years old)

Participants drew social connection and a sense of belonging from being part of a masculine milieu celebrating the love of football. Besides, the participants often mentioned how much consideration they showed one another on and off the field:

"Of course, you bump into each other and stuff like that, but we really don't take any chances in that regard... if someone passes by, then you don't obstruct him. So in that way, perhaps due to our situation, we are a bit more considerate of each other." (August, 69 years old)

\section{Discussion}

The findings of the current study suggest that risk of injury in the context of community-based football may give men with prostate cancer an opportunity to embody some masculine ideals.

In addition to significant health benefits (Krustrup et al., 2010), football constitutes a novel rehabilitation strategy involving taking control for one's actions, forcing the disease into the background by replacing the patient identity with a masculine athlete identity. Central to this exchange is a focus on strength-based masculinity. When asked about the impact and meaning of being injured during football, the men decidedly and authentically spoke about what they had gained through football rather than what they had or would loose from being injured. In the light of the limits invoked on the men by prostate cancer and its treatment(s), including the experience of loss of masculinity, the risk and/or experience of being injured through football appeared not only harmless but also potentially beneficial to the men's perception of themselves as men and not as patients. In this regard, competitive contact sports, including football, may benefit the physical and mental well-being of men with prostate cancer, as well as increase recruitment and retention to physical activity-based rehabilitation programs.

However, although the current study indicates that men with prostate cancer may not suffer the negative consequences of sports injuries to the degree assumed in the existing literature (Covassin et al., 2015; Rice et al., 2016; Young, 2004), Nixon (1996) and Young (2004), who are critical of the sociology of injuries, believe that striving for masculine ideals can be problematic because it causes athletes and therapists to neglect and normalize injuries, perhaps leading to poorer treatment of injuries and illness outcomes. Specifically, Roderick (2006) examined how professional footballers become, or perceive themselves as being, stigmatized when they are injured or in pain, and concluded that pain and injury are normalized within the culture of professional football, meaning that players often find themselves in health-compromising situations. Accordingly, while the current study suggests taking a more positive approach to sports injuries, the participants' apparent acceptance of injuries must not overshadow the negative effects that sports injuries can have on patients. Furthermore, for some men, characterized by an unwillingness or inability to embody an athletic identity, the risk and experience of injuries may be unacceptable. 
As such, some men are likely to need more governance and support to be safe and sustain their enjoyment and involvement in community-based football. To help men with prostate cancer make an informed choice about football that takes into account their personal values and preferences in relation to the risk of injuries, we propose the use of a decision aid tool (Figure 2). This tool, which of course should be properly evaluated before implemented in clinical practice, presents nine statements based on findings from the current study, which require the individual man to think through what is important to them and address the "trade-offs" they need to make. Accordingly, such a tool could support a balanced communication between clinicians and patients and thus facilitate shared decision making in relation to football as preferred choice of exercise.

To the best of our knowledge, no other studies have examined the effect of sports injuries or the risk of them in the context of men living with prostate cancer. As such, the findings of this study stand alone in opposition to a large body of literature on the negative consequences of sports injuries. As a result, it would be valuable to confirm whether or not our study failed to identify some of the negative effects observed by previous researchers. Furthermore, a recent debate among leading exercise-oncology researchers (Hardcastle \& Cohen, 2018) emphasized the importance of the active involvement of clinicians in exercise promotion among cancer survivors, and indicated that clinicians' concerns about safety constitute a major barrier in the promotion of home-based (unsupervised) exercise. Because of the relatively high risk of football injuries, fear of injury is likely to inhibit health professionals' endorsement, let alone referral to such programs. The current study, however, challenges this belief by indicating that injuries may be an acceptable risk for some men garnering an array of benefits including social connectedness and improved affect. Further studies are warranted exploring attitudes of health professionals toward referral of men with prostate cancer to community-based football.

The global theme Injury-induced reinforced masculinity introduced in this study is not claimed as generalizable but might instead prompt future investigations of novel rehabilitation programs. The participants in the current study chose to play football, which implies that they considered the risk of injury upon entering the study. This may infer that individuals with a negative attitude toward sports and related injuries opted out prior to commencement of the study. As a result, interviewing older men with prostate cancer who declined to participate about their perception of the risk of injury would provide additional valuable insights. This study was designed to apply to men only, which is why it is important to

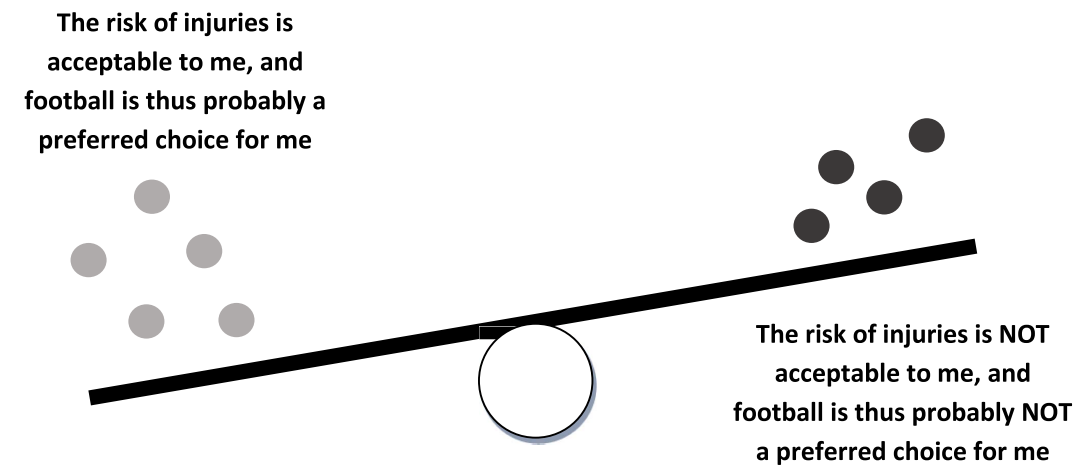

An injury would hinder my participation in other activities more important to me than football
AGREE / DISAGREE
An injury is nothing compared to being diagnosed with prostate cancer; I've been through worse
AGREE / DISAGREE
To me, the risk of being injured is a natural part of playing football
AGREE / DISAGREE
AGREE / DISAGREE
I feel that I need to be extra careful not to get injured because my body is especially vulnerable
I would be embarrassed telling people that I got injured from playing football
AGREE / DISAGREE
Playing football would make me feel more as a man, and less as a patient
AGREE / DISAGREE
Even if I get injured, I would still fell part of team and benefit from the camaraderie
AGREE / DISAGREE
My body aches a little every day anyhow, and an injury wouldn't make a difference
AGREE / DISAGREE
If I get injured, I would expect professional help free-of-charge
AGREE / DISAGREE

Use these statements to help you decide whether community-based football including the risk of being injured is an acceptable exercise option to you. A majority of dark grey answers indicate that football, including the risk of being injured, may not be an acceptable exercise option for you; whereas a majority of light grey answers indicate that you may benefit psychologically from participation in community-based football, and that the risk of being injured is largely acceptable to you.

Figure 2 - Decision aid proposal. 
bear in mind that the perceptions of women and men toward age and body might differ (Bullington, 2006). Women, and for that matter diverse groups of men, may not react in the same way to sports injuries as the men in our study. This study focused exclusively on men with prostate cancer and may be transferable to other cancer diagnoses or chronic diseases that entail the same degree of a loss of masculinity. As a result, more studies are needed on the impact of sports injuries in other clinical populations. Furthermore, and in the light of masculinities theory suggesting that gender is relational (Connell, 1995), examination of the experiences of the men's partners might add value to this work.

The perception of what constitutes risk and harm versus benefit varies contextually, which is why integrating patient preferences and autonomy to health promotion efforts is important (Sokol, 2013). According to our study, taking a positive approach to sports injuries is warranted, though men's widespread acceptance of injuries must not overshadow the negative effects sports injuries can have on prostate cancer rehabilitation. When considering referral to exercise programs, members of the prostate cancer care team should be aware that a proportion of men with prostate cancer view the risk of injuries as acceptable.

\section{Conclusion}

The current study examined the acceptability of the risk of injury associated with community-based football among men with prostate cancer. The data indicated that the risk and incidence of injury may have a positive impact on men with prostate cancer by reinforcing their sense of masculinity through alignment with idealized masculine identities.

\section{Acknowledgments}

The Danish foundation TrygFonden funded this study (grant number 106471). We would especially like to thank the men who agreed to share their perspectives and experiences with us. We would also like to acknowledge the FC Prostate Community steering group for valuable insights and inputs concerning the planning and reporting of this study. Finally, we would like to thank Malene Kronborg for her help in preparation of Table 1 .

\section{References}

Anderson, C., \& Kirkpatrick, S. (2016). Narrative interviewing. International Journal of Clinical Pharmacy, 38(3), 631-634. PubMed ID: 26613739 doi:10.1007/s11096-015-0222-0

Attride-Stirling, J. (2001). Thematic networks: An analytic tool for qualitative research. Qualitative Research, 1, 385-405. doi:10. 1177/146879410100100307

Bechis, S.K., Carroll, P.R., \& Cooperberg, M.R. (2011). Impact of age at diagnosis on prostate cancer treatment and survival. Journal of Clinical Oncology, 29, 235-241. PubMed ID: 21135285 doi:10. 1200/JCO.2010.30.2075

Bjerre, E., Bruun, D.M., Tolver, A., Brasso, K., Krustrup, P., Johansen, C., . . Midtgaard, J. (2016). Effectiveness of community-based football compared to usual care in men with prostate cancer: Protocol for a randomised, controlled, parallel group, multicenter superiority trial (The FC Prostate Community Trial). BMC Cancer, 16(1), 767. PubMed ID: 27716218 doi:10.1186/s12885-016-2805-0

Bradley, B.H., Baur, J.E., Banford, C.G., \& Postlethwaite, B.E. (2013). Team players and collective performance: How agreeableness affects team performance over time. Small Group Research, 44, 680-711. doi:10.1177/1046496413507609

Bruner, J. (1990). Acts of meaning. Cambridge, MA: Harvard University Press.

Bruun, D.M., Bjerre, E., Krustrup, P., Brasso, K., Johansen, C., Rorth, M., \& Midtgaard, J. (2014). Community-based recreational football: A novel approach to promote physical activity and quality of life in prostate cancer survivors. International Journal of Environmental Research and Public Health, 11(6), 5567-5585. PubMed ID: 24865394 doi:10.3390/ijerph110605567

Bruun, D.M., Krustrup, K., Hornstrup, T., Uth, J., Brasso, K., Roerth, M., . . . Midtgaard, J. (2013). 'All boys and men can play football': A qualitative investigation of recreational football in prostate cancer patients. Scandinavian Journal of Medicine and Science in Sports, 24(Suppl. 1), 113-121. PubMed ID: 24944135 doi:10.1111/sms. 12193

Bryson, L. (1987). Sport and the maintenance of masculine hegemony. Women's Studies International Forum, 10, 349-360. PubMed ID: 30172246 doi:10.1016/0277-5395(87)90052-5

Bullington, J. (2006). Body and self: A phenomenological study on the ageing body and identity. Medical Humanities, 32, 25-31. PubMed ID: 23674744 doi:10.1136/jmh.2004.000200

Chipperfield, K., Fletcher, J., Millar, J., Brooker, J., Smith, R., Frydenberg, M., . . . Burney, S. (2013). Factors associated with adherence to physical activity guidelines in patients with prostate cancer. Psychooncology, 22(11), 2478-2486. PubMed ID: 23749430 doi:10.1002/pon. 3310

Christakou, A., \& Lavallee, D. (2009). Rehabilitation from sports injuries: From theory to practice. Perspect Public Health, 129(3), 120-126. PubMed ID: 19514635 doi:10.1177/1466424008094802

Connell, R.W. (2008). Masculinity construction and sports in boys' education: A framework for thinking about the issue. Sport, Education and Society, 13, 131-145. doi:10.1080/1357332080 1957053

Connell, R.W. (1995). Masculinities. Cambridge, England: Polity Press. Cormie, P., Oliffe, J.L., Wootten, A.C., Galvão, D.A., Newton, R.U., \& Chambers, S.K. (2016). Improving psychosocial health in men with prostate cancer through an intervention that reinforces masculine values - exercise. Psycho-Oncology, 25, 232-235. PubMed ID: 26086938 doi: $10.1002 /$ pon.3867

Cormie, P., Zopf, E.M., Zhang, X., \& Schmitz, K.H. (2017). The impact of exercise on cancer mortality, recurrence, and treatment-related adverse effects. Epidemiologic Reviews, 39(1), 71-92. PubMed ID: 28453622 doi:10.1093/epirev/mxx007

Covassin, T., Beidler, E., Ostrowski, J., \& Wallace, J. (2015). Psychosocial aspects of rehabilitation in sports. Clinical Sports Medicine, 34(2), 199-212. doi:10.1016/j.csm.2014.12.004

Crossley, M.L. (2003). 'Would you consider yourself a healthy person?': Using focus groups to explore health as a moral phenomenon. Journal of Health Psychology, 8(5), 501-514. PubMed ID: 19177713 doi:10. $1177 / 13591053030085003$

Drummond, M.J.N. (2002). Sport and images of masculinity: The meaning of relationships in the life course of "Elite" male athletes. The Journal of Men's Studies, 10(2), 129-141. PubMed ID: 30158157 doi:10. 3149/jms. 1002.129

Handberg, C., Lomborg, K., Nielsen, C.V., Oliffe, J.L., \& Midtgaard, J. (2015). Understanding male cancer patients' barriers to participating in cancer rehabilitation. European Journal of Cancer Care (England), 24(6), 801-811. PubMed ID: 26223855 doi:10.1111/ ecc. 12358

Hardcastle, S.J., \& Cohen, P.A. (2018). Reply to S.C. Adams et al, C. Lopez et al, and R.U. Newton et al. Journal of Clinical Oncology, 
36(9), 928-930. PubMed ID: 29373095 doi:10.1200/JCO.2017. 76.8218

Kroshus, E., Garnett, B., Hawrilenko, M., Baugh, C.M., \& Calzo, J.P. (2015). Concussion under-reporting and pressure from coaches, teammates, fans, and parents. Social Science \& Medicine, 134, 66-75. PubMed ID: 25917137 doi:10.1016/j.socscimed.2015. 04.011

Krustrup, P., Aagaard, P., Nybo, L., Petersen, J., Mohr, M., \& Bangsbo, J. (2010). Recreational football as a health promoting activity: A topical review. Scandinavian Journal of Medicine \& Science in Sports, 20(Suppl. 1), 1-13.

Krustrup, P., Nielsen, J.J., Krustrup, B.R., Christensen, J.F., Pedersen, H., Randers, M.B., . . . Bangsbo, J. (2009). Recreational soccer is an effective health-promoting activity for untrained men. British Journal of Sports Medicine, 43(11), 825-831. PubMed ID: 19098116 doi:10. 1136/bjsm.2008.053124

López, A.M., Pena, M.A., Hernández, R., Val, F., Martín, B., \& Riancho, J.A. (2005). Fracture risk in patients with prostate cancer on androgen deprivation therapy. Osteoporosis International, 16, 707-711. doi:10. 1007/s00198-004-1799-7

Nixon, H.L. (1996). Explaining pain and injury attitudes and experiences in sport in terms of gender, race, and sports status factors. Journal of Sport \& Social Issues, 20, 33-44. doi:10.1177/019372396020001004

Podlog, L., Heil, J., \& Schulte, S. (2014). Psychosocial factors in sports injury rehabilitation and return to play. Physical Medicine and Rehabilitation Clinics of North America, 25(4), 915-930. PubMed ID: 25442166 doi:10.1016/j.pmr.2014.06.011

Putukian, M. (2016). The psychological response to injury in student athletes: A narrative review with a focus on mental health. British Journal of Sports Medicine, 50(3), 145-148. PubMed ID: 26719498 doi:10.1136/bjsports-2015-095586

Rice, S.M., Purcell, R., De Silva, S., Mawren, D., McGorry, P.D., \& Parker, A.G. (2016). The mental health of elite athletes: A narrative systematic review. Sports Medicine, 46(9), 1333-1353. PubMed ID: 26896951 doi:10.1007/s40279-016-0492-2

Riessman, C.K. (1993). Narrative analysis: Qualitative research methods. Newbury Park, CA: Sage.

Roderick, M. (2006). Adding insult to injury: Workplace injury in English professional football. Sociology Health Illness, 28(1), 76-97. PubMed ID: 16509943
Sanderson, J., Weathers, M., Grevious, A., Tehan, M., \& Warren, S. (2016). A hero or sissy? Exploring Media framing of NFL quarterbacks injury decisions. Communication \& Sport, 4, 3-22. doi:10. 1177/2167479514536982

Shephard, R.J. (2017). Physical activity and prostate cancer: An updated review. Sports Medicine, 47(6):1055-1073. PubMed ID: 27844337 doi:10.1007/s40279-016-0648-0

Smith, B., \& Sparkes, A.C. (2005). Men, sport, spinal cord injury, and narratives of hope. Social Science and Medicine, 61, 1095-1105. PubMed ID: 15955409 doi:10.1016/j.socscimed.2005.01.011

Sokol, D.K. (2013). "First do no harm" revisited. BMJ, 347, f6426. PubMed ID: 24163087 doi:10.1136/bmj.f6426

Spector-Mersel, G. (2006). Never-aging stories: Western hegemonic masculinity scripts. Journal of Gender Studies, 15, 67-82. doi:10. 1080/09589230500486934

Theberge, N. (1997). "It's part of the game": Physicality and the production OG gender in women's hockey. Gender and Society, 11, 69-87. doi:10.1177/089124397011001005

Uth, J., Hornstrup, T., Christensen, J.F., Christensen, K.B., Jorgensen, N.R., Helge, E.W., . . Krustrup, P. (2016). Football training in men with prostate cancer undergoing androgen deprivation therapy: activity profile and short-term skeletal and postural balance adaptations. European Journal of Applied Physiology, 116(3), 471-480. PubMed ID: 26620651 doi:10.1007/s00421-015-3301-y

Uth, J., Hornstrup, T., Christensen, J.F., Christensen, K.B., Jorgensen, N.R., Schmidt, J.F., . . . Helge, E.W. (2016). Efficacy of recreational football on bone health, body composition, and physical functioning in men with prostate cancer undergoing androgen deprivation therapy: 32-week follow-up of the FC prostate randomised controlled trial. Osteoporosis International, 27(4), 1507-1518. PubMed ID: 26572756 doi:10.1007/s00198-015-3399-0

van den Hoonaard, D.K. (2009). "I was the man": The challenges of masculinity for older men. In Z.D Buchholz, S.K Boyce (Eds.), Masculinity: Gender roles, characteristics and coping (pp. 69-84). New York: Nova Science Publishers.

Young, K. (2004). Sporting bodies, damaged selves, sociological studies of sports-related injury, Amsterdam, Netherlands: Elsevier.

Young, K., McTeer, W., \& White, P. (1994). Body talk - Male athletes reflect on sport, injury and pain. Sociology of Sport Journal, 11, 175-194. doi:10.1123/ssj.11.2.175 